\title{
EFEITO RESIDUAL DO POTÁSSIO NO SISTEMA DE CULTIVO SOJA-MILHO SAFRINHA NO CERRADO MATO-GROSSENSE
}

\author{
Edilson Cavalli ${ }^{1 *}$, Anderson Lange ${ }^{2}$ \\ ${ }^{1}$ Doutorando em agricultura tropical e subtropical, IAC - Instituto Agronômico de Campinas, Campinas (SP) \\ *E-mail: edilso_c@ @otmail.com \\ ${ }^{2}$ Docente do Instituto de Ciências Agrárias e Ambientais, UFMT - Universidade Federal de Mato Grosso, \\ Sinop (MT).
}

RESUMO: No estado de Mato Grosso a sucessão soja-milho safrinha é amplamente praticada, assim a adubação deve ser realizada pensando no sistema como um todo, não apenas na cultura presente no campo, desta forma o conhecimento do efeito residual da aplicação de fertilizantes é de suma importância. Neste trabalho objetivou-se estudar o efeito de doses de potássio na cultura da soja e seu efeito residual influenciado pelo consórcio com braquiária, nos cultivos sucessivos, no sistema soja-milho safrinha. $\mathrm{O}$ estudo foi realizado no município de Sorriso-MT. Em delineamento de blocos casualizados, com cinco doses de potássio $\left(0,40,80,160\right.$ e $320 \mathrm{~kg} \mathrm{ha}^{-1}$ de $\left.\mathrm{K}_{2} \mathrm{O}\right)$ na cultura da soja, e o efeito residual nas safras subsequentes (milho, soja e milho), com cinco repetições. Após a colheita do primeiro cultivo, as parcelas foram subdivididas (com e sem a presença de braquiária) visando aumentar a ciclagem de potássio. Não se tem efeito das doses de K na soja, contudo se tem efeito residual no milho plantado em sequencia. A soja não responde a aplicação de potássio em sistemas com teor de K no solo adequado. Quando sob estresse hídrico, mesmo com teores altos de $\mathrm{K}$ no solo, o milho responde ao aumento de $\mathrm{K}$ no solo. Já sob condições climáticas adequadas, com chuvas bem distribuídas não se observa resposta. O primeiro cultivo de milho apresentou resposta para altura de espiga, massa de 100 grãos e produção relativa, com incremento de $28 \%$. A produção acumulada nas quatro safras apresentou resposta, com incremento de $10 \%$.

Palavras-chave: Ciclagem de nutrientes. Manejo de culturas. Sistemas mistos.

\section{POTASSIUM RATES AND THEIR RESIDUAL EFFECT ON THE SOY-CORN CROPS SYSTEM}

\begin{abstract}
In the state of Mato Grosso, the soybean-corn succession is widely practiced, so fertilization must be carried out with the whole system in mind, not only in the present field culture, in this way the knowledge of the residual effect of the application of fertilizers and of great importance. The objective of this work was to study the effect of potassium rates and their residual effect on successive crops in soybean-corn crop system. The study was carried out in the city of Sorriso-MT. In randomized block design with five rates of potassium $\left(0,40,80,160\right.$ and $320 \mathrm{~kg} \mathrm{ha}^{-1}$ of $\left.\mathrm{K}_{2} \mathrm{O}\right)$ in the soybean crop. residual effect on subsequent crops (corn, soybean and corn), with five replicates. After harvesting
\end{abstract}

Cultura Agronômica, Ilha Solteira, v.27, n.2, p.310-326, 2018 
the first crop, the plots were subdivided (with and without the presence of brachiaria) in order to increase the potassium cycling. There is no effect of $\mathrm{K}$ rates on soybean, however, if there is a residual effect on maize planted in sequence. Soybean does not respond to potassium application in systems with adequate soil $\mathrm{K}$ content. When under water stress, even with high levels of $\mathrm{K}$ in the soil, the corn responds to the increase of $\mathrm{K}$ in the soil. Already under suitable climatic conditions, with rains well distributed no answer is observed. The first corn crop presented response to ear height, mass of 100 grains and relative yield, with an increase of $28 \%$. The accumulated production in the four harvests presented a response, with an increase of $10 \%$.

Key words: Nutrient cycling. Crop management. Mixed systems.

\section{INTRODUÇÃO}

O Estado de Mato Grosso é um dos principais produtores de soja e milho do Brasil, respondendo por $25 \%$ da produção de milho e $30 \%$ da produção de soja (CONAB, 2015), para isto o estado utiliza aproximadamente $18 \%$ do total de fertilizantes comercializados no país (IPNI, 2014). Mesmo assim as pesquisas realizadas na região ainda são incipientes, sendo utilizadas recomendações provenientes de pesquisas de outras regiões do Brasil.

O potássio (K) tem grande importância do para o desenvolvimento das culturas devido a grande quantidade extraída pelas plantas (RAIJ et al., 1997). Mesmo apresentando muitas funções e tendo uma grande extração pelas plantas, respostas a adubação potássica não são muito expressivas, devido ao plantio em áreas com teor de $\mathrm{K}$ no solo em níveis considerados adequados (TAKASU et al., 2014). Sintomas da falta de K aparecem somente após alguns anos de cultivo, caso a adubação não seja bem manejada.

A cultura da soja apresenta baixa resposta às doses de $\mathrm{K}$ quando o teor no solo esta adequado, normalmente as respostas, quando ocorrem, são observadas após alguns anos de cultivos, quando a adubação potássica é negligenciada, não se repondo o $\mathrm{K}$ removido do solo, seja por lixiviação ou exportação pelas culturas (MASCARENHAS et al., 1994; SCHERER, 1998a; SCHERER, 1998b; LOPES, 2007). Já a cultura do milho é mais responsiva a adubação potássica, principalmente em solos de baixa fertilidade (WENDLING et al., 2008; COELHO, 2006). Isto se deve a grande extração de K pela cultura do milho, variando de 311 a $317 \mathrm{~kg} \mathrm{ha}^{-1}$ (BORGES, 2006; VON PINHO, 2009).

A cultura da soja apresenta grande exportação do K absorvido, ultrapassando $50 \%$, junto com os grãos (OLIVEIRA JUNIOR et al., 2013), assim ficando pouco K na palhada residual para a safra subsequente. $\mathrm{O}$ milho por sua vez apresenta grande extração de $\mathrm{K}$, contudo apresenta uma baixa exportação, $20 \%$ apenas (EMPRAPA, 2011), assim os restos culturais se tornam uma grande fonte de $\mathrm{K}$ para as culturas subsequentes. A adição da braquiária no sistema (consórcio milho-braquiária) visa aumentar ainda mais o $\mathrm{K}$ ciclado no

Cultura Agronômica, Ilha Solteira, v.27, n.2, p.310-326, 2018 
sistema, extraindo $\mathrm{K}$ das camadas mais profundas e liberando-o sobre o solo durante a decomposição da palhada, aumentando a eficiência de uso do K aplicado.

A dinâmica do $\mathrm{K}$ no solo tem grande relação com o regime hídrico do local. $\mathrm{O}$ nutriente é facilmente perdido por lixiviação, seja pela aplicação muito acima da capacidade de armazenamento do solo (CTC) ou por precipitações muito elevadas (BRADY e WEIL, 2013). Assim na região norte de Mato Grosso, no sistema soja-milho safrinha as maiores perdas de K são durante o cultivo da soja, onde se concentra a maior precipitação. Contudo a baixa precipitação durante o cultivo de milho impõe uma grande limitação à absorção deste, devido à absorção de K estar ligada ao seu transporte na solução do solo, influenciada pela umidade (PETTER et al., 2012).

Neste trabalho objetivou-se estudar o efeito de doses de K na cultura da soja e seu efeito residual, influenciado pelo consórcio com braquiária, nos cultivos sucessivos, no sistema soja-milho safrinha.

\section{MATERIAL E MÉTODOS}

\section{Caracterização do local}

O estudo foi conduzido no município de Sorriso-MT ( $\mathrm{S}=12^{\circ} 31^{\prime} 06^{\prime \prime}$; W= 55 40'22" e altitude de $365 \mathrm{~m}$ ), no decorrer dos anos agrícolas 2013-14 e 2014-15. As variações climáticas ocorridas no decorrer do desenvolvimento dos experimentos estão dispostas na Figura 1.

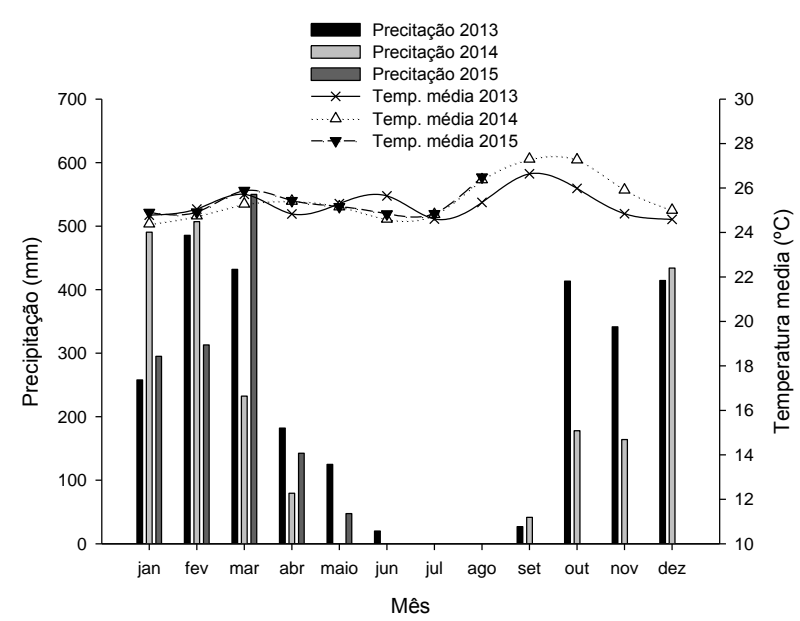

Figura 1. Precipitação acumulada e temperatura média, para o município de Sorriso, de janeiro de 2013 a agosto de 2015.

Fonte: Fundação Mato Grosso, Sorriso-MT.

O clima da região é classificado como AW, tropical quente, segundo classificação de Köppen, possui duas estações do ano bem definidas, são elas o verão chuvoso e o inverno seco. O solo é classificado como Latossolo Vermelho-Amarelo (EMBRAPA, 2013), Antes da implantação do experimento foram coletadas 10 amostras simples, estas foram 
homogeneizadas e preparadas uma amostra composta, sendo nesta feitas a análise química e de textura do solo (EMBRAPA, 2017), com os resultados apresentados na Tabela 1. O experimento foi conduzido em área cultivada no sistema de semeadura direta, soja-milho safrinha, havia doze anos e que vinha recebendo aplicações anuais próximas a $160 \mathrm{~kg} \mathrm{ha}{ }^{-1}$ $\mathrm{K}_{2} \mathrm{O}$, dividida entre as culturas.

Tabela 1. Caracterização inicial do solo antes da implantação do experimento.

\begin{tabular}{|c|c|c|c|c|}
\hline & \multicolumn{4}{|c|}{ Profundidade $(\mathrm{cm})$} \\
\hline & $0-10$ & $10-20$ & $20-40$ & $40-60$ \\
\hline \multicolumn{5}{|l|}{ Química } \\
\hline $\mathrm{pH}^{*}$ & 5,44 & 5,43 & 5,23 & 5,24 \\
\hline M.O. $\left(\mathrm{g} \mathrm{dm}^{-3}\right)$ & 3,92 & 3,75 & 2,81 & 2,20 \\
\hline $\mathrm{P}\left(\mathrm{mg} \mathrm{dm}^{-3}\right)$ & 16,01 & 5,01 & 3,07 & 1,68 \\
\hline $\mathrm{K}\left(\mathrm{mg} \mathrm{dm}^{-3}\right)$ & 95,60 & 84,00 & 66,20 & 40,00 \\
\hline $\mathrm{Ca}\left(\mathrm{cmol}_{\mathrm{c}} \mathrm{dm}^{-3}\right)$ & 4,00 & 2,18 & 1,19 & 0,70 \\
\hline $\mathrm{Mg}\left(\mathrm{cmol}_{\mathrm{c}} \mathrm{dm}^{-3}\right)$ & 1,72 & 0,87 & 0,70 & 0,36 \\
\hline $\mathrm{H}+\mathrm{Al}\left(\mathrm{cmol}_{\mathrm{c}} \mathrm{dm}^{-3}\right)$ & 7,34 & 6,46 & 6,10 & 3,90 \\
\hline CTC $\left(\mathrm{cmol}_{\mathrm{c}} \mathrm{dm}^{-3}\right)$ & 13,31 & 9,73 & 8,16 & 5,06 \\
\hline $\mathrm{V}(\%)$ & 44,86 & 33,59 & 25,23 & 22,98 \\
\hline \multicolumn{5}{|l|}{ Textura do solo } \\
\hline Argila $\left(\mathrm{g} \mathrm{kg}^{-1}\right)$ & 530 & 553 & 586 & 607 \\
\hline Areia $\left(\mathrm{g} \mathrm{kg}^{-1}\right)$ & 307 & 297 & 270 & 252 \\
\hline Silte $\left(\mathrm{g} \mathrm{kg}^{-1}\right)$ & 163 & 150 & 144 & 141 \\
\hline
\end{tabular}

\section{Implantação do experimento}

O experimento foi implantado no dia 26 de outubro de 2013, com a semeadura e adubação da soja, safra 2013/14, e os tratamentos nesta ocasião foram doses de $\mathrm{K}_{2} \mathrm{O}(0,40$, 80,160 e $320 \mathrm{~kg} \mathrm{ha}^{-1}$ ) na forma de $\mathrm{KCl}$, em delineamento de blocos casualizados, com cinco repetições. As parcelas apresentavam a dimensão de 6,6 x 6,0 m, com a semeadura realizada no espaçamento de $0,55 \mathrm{~m}$ entre fileiras. No momento da semeadura realizou-se a determinação da massa seca residual do milho sobre o solo, esta realizada por meio de lançamento aleatório de um gabarito de $0,25 \mathrm{~m}^{2}(0,5 \mathrm{x} 0,5 \mathrm{~m}) 15$ vezes na área, e analisado o teor de $\mathrm{K}$ desta palhada. $\mathrm{O}$ solo estava coberto com $14.176 \mathrm{~kg} \mathrm{ha}^{-1}$ de massa seca residual do milho, e esta continha em média $162 \mathrm{~kg} \mathrm{ha}^{-1}$ de $\mathrm{K}$.

A cultivar utilizada foi a GB 874, devido à alta quantidade de palhada, de alta relação $\mathrm{C} / \mathrm{N}$, previamente ao plantio foram aplicados $20 \mathrm{~kg} \mathrm{ha}^{-1} \mathrm{de} \mathrm{N}$, na forma de ureia e

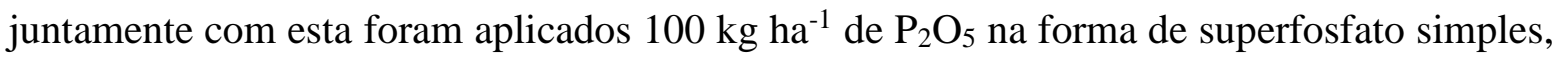
estas realizadas a lanço em área total. A colheita foi realizada no dia 27 de fevereiro de 2014.

Cultura Agronômica, Ilha Solteira, v.27, n.2, p.310-326, 2018 
Para avaliar o efeito residual da adubação potássica, após a colheita da soja, safra 2013-14, as parcelas foram subdivididas, semeando-se a lanço a braquiária (Urochloa ruzizienses) na metade das parcelas e após este procedimento, semeou-se o milho, gerando o consórcio, assim as subparcelas passando a medir 3,3 x 6,0 m. A utilização da braquiária teve por objetivo aumentar a ciclagem de $\mathrm{K}$ de camadas mais profundas, este sendo disponibilizados para culturas subsequentes. Para avaliar o efeito residual das doses de K da soja, a adubação na cultura do milho foi realizada igualmente em todo o experimento, com aplicação de base de $80 \mathrm{~kg} \mathrm{ha}^{-1}$ de $\mathrm{N}$ e $80 \mathrm{~kg} \mathrm{ha}^{-1}$ de $\mathrm{K}_{2} \mathrm{O}$, na forma de $400 \mathrm{~kg} \mathrm{ha}^{-1}$ de formulado comercial (20-00-20), sendo a aplicação 16 dias após a semeadura (estádio V2), e cobertura com $60 \mathrm{~kg} \mathrm{ha}^{-1}$ de $\mathrm{N}$ na forma de ureia, 33 dias após a semeadura (estádio V5).

A semeadura da braquiária foi realizada a lanço antes da colheita da soja, no dia 27 de fevereiro de 2014, com utilização de $5 \mathrm{~kg} \mathrm{ha}^{-1}$ de sementes puras viáveis. Houve má germinação da braquiária e por isto foi realizado nova semeadura no dia 21 de março de 2014, na entrelinha do milho, com utilização de $6 \mathrm{~kg} \mathrm{ha}^{-1}$ de sementes puras viáveis, porém a falta de chuvas não possibilitou bom estabelecimento desta. A semeadura do milho, safra 2013/14, foi realizada no dia 05 de março de 2014, sobre os restos culturais da soja e o hibrido utilizado foi o DKB 390 VT PRO 2, colhida em 10 de julho de 2014. Após a colheita manual das espigas, as plantas foram todas fracionadas com auxílio de um facão e distribuídas sobre o solo de forma homogenia, na área correspondente da subparcela, sendo o material fracionado em pedaços de aproximadamente $0,50 \mathrm{~m}$.

No dia 25 de setembro de 2014 foi realizada a semeadura da soja, safra 2014/15, sobre os restos culturais do milho, visando avaliar o efeito residual da adubação potássica e do aproveitamento do $\mathrm{K}$ presente na palhada do milho e da braquiária. A cultivar utilizada foi a TMG 132, adubada com $108 \mathrm{~kg} \mathrm{ha}^{-1}$ de $\mathrm{P}_{2} \mathrm{O}_{5}$ na forma de superfosfato simples, a lanço em pré-semeadura e a colheita ocorreu no dia 20 de janeiro de 2015.

Também visando avaliar o efeito residual da adubação potássica foi realizada a semeadura do milho, safra 2014/15, no dia 2 de fevereiro de 2015, sobre os restos culturais da soja, hibrido utilizado foi o DKB $245 \mathrm{RR}$, a adubação foi constituída de $100 \mathrm{~kg} \mathrm{ha}^{-1}$ de N, na forma de ureia sendo aplicado metade no estádio V2 e metade no V4, a colheita foi realizada no dia 20 de junho de 2015 .

\section{Coleta das amostras}

Na cultura da soja foi avaliado o acumulo total de massa de matéria seca (MMS) quando a planta se encontrava em R7, que segundo Cruz et al. (2010) é o estádio de máximo acumulo de massa seca para soja semeadas na época preferencial de plantio. Sendo colhidas duas plantas inteiras por parcela, estas secas em estufas de circulação de ar forçada a $65^{\circ} \mathrm{C}$ até atingir peso constante, e após pesagem, transformadas para $\mathrm{kg} \mathrm{ha}^{-1}$ de MMS, com base no estande da parcela.

Quando atingiu a maturidade fisiológica foi realizada a colheita de forma manual, colhendo dez plantas nas duas linhas centrais para serem efetuadas as avaliações dos 
seguintes parâmetros: altura de plantas e de inserção da primeira vagem; número de vagens por planta, grãos por vagens e massa de cem grãos. Para a determinação da produtividade foram colhidos 6,6 $\mathrm{m}^{2}$, trilhados com auxílio de uma trilhadora mecânica (Maqtron-B350) e os grãos pesados somados as produtividades das 10 plantas e corrigidos para $13 \%$ de umidade.

$\mathrm{Na}$ cultura do milho safra 2013-14 quando atingiu a maturidade fisiológica foi realizada a colheita de forma manual, colhendo dez plantas nas duas linhas centrais para serem efetuadas as avaliações dos seguintes parâmetros: MMS residual obtida com a pesagem das 10 plantas inteiras excetuando-se a espiga, estas secas em estufas de circulação de ar forçada a $65^{\circ} \mathrm{C}$ até atingir peso constante, e após pesagem, transformadas para $\mathrm{kg} \mathrm{ha}^{-1}$ de MMS, com base no estande da subparcela; altura de plantas e de inserção da espiga; comprimento e diâmetro do colmo abaixo da espiga: número de grãos por fileira, fileiras por espiga; comprimento e diâmetro da espiga; e diâmetro do sabugo; massa de cem grãos. Para a determinação da produtividade foram colhidos $8,8 \mathrm{~m}^{2}$, trilhados com auxílio de uma trilhadora mecânica (Maqtron-B350) e os grãos pesados somados as produtividades das 10 plantas e corrigidos para $13 \%$ de umidade.

Na cultura do milho safra 2014/15 foram seguidos os mesmos procedimentos sendo que se realizou apenas a avaliação de número de grãos por fileira, fileiras por espiga; massa de cem grãos. E para a determinação da produtividade foram colhidos $6,6 \mathrm{~m}^{2}$.

Foi calculada a produção de grãos acumulada, durante os quatro cultivos, somando-se os valores de produtividade, calculada apenas para as parcelas, assim utilizando a média da produtividade das subparcelas dentro de cada dose.

A produtividade foi convertida para produção relativa. Para o cultivo soja 2013-14 e para a produção acumulada foi utilizado como tratamento padrão o tratamento controle sem aplicação de K. E para os cultivos da soja 2014-15 e ambas as safras de milho foi usado o tratamento controle - sem aplicação de $\mathrm{K}$ e sem a presença do consórcio. A produção relativa foi calculada pela formula:

$$
(P R)=\left(P G_{p} * 100 / P G_{t c}\right), e m \%
$$

Em que: $\mathrm{PR}=$ produção relativa; $\mathrm{PG}_{\mathrm{p}}=$ produtividade de grãos da parcela a ser convertida e $\mathrm{PG}_{\mathrm{tc}}=$ produtividade de grãos do tratamento controle.

\section{Análise estatística}

Os resultados foram submetidos à análise de variância, quando estes foram significativos submetidos à análise de regressão para o efeito das doses de $\mathrm{K}$ e ao teste de Tukey para o fator presença e ausência de braquiária, ambos com o nível de $5 \%$ de probabilidade. 


\section{RESULTADOS E DISCUSSÃO}

Na cultura da soja durante os dois anos de cultivos nenhuma das variáveis avaliadas foram significativamente influenciadas pelas doses de $\mathrm{K}$, pelo seu efeito residual e consórcio com braquiária (Tabelas 2 e 3). A produção de grãos manteve-se praticamente estável em ambas as safras, a produtividade no tratamento sem adição de K na safra 201314 foi de $3.608 \mathrm{~kg} \mathrm{ha}^{-1}$, com uma variação máxima de $3 \%$ entre as doses. Na safra 2014-15 a produtividade no tratamento sem adição de $\mathrm{K}$ e sem consórcio foi de $3.011 \mathrm{~kg} \mathrm{ha}^{-1} \mathrm{com}$ a variação máxima entre os tratamentos de $8 \%$. A menor produtividade na safra 2014-15 devido ao acamamento da soja previamente a floração, prejudicado a mesma.

Tabela 2. Características agronômicas: Altura de planta (ALT), Altura de inserção da primeira vagem (IPV), número de vagens por planta (VPP), grãos por vagem (GV), massa de 100 grãos (M100) e massa de seca (MS) e produção relativa (PROD) da soja safra 201314 em função das doses de K aplicadas, Sorriso-MT.

\begin{tabular}{|c|c|c|c|c|c|c|c|}
\hline \multirow[t]{2}{*}{ Doses } & ALT & IPV & VPP & GV & M100 & MS & PROD \\
\hline & \multicolumn{2}{|c|}{----cm---- } & \multicolumn{2}{|c|}{ Quantidade } & $\mathrm{g}$ & $\mathrm{kg} \mathrm{ha}^{-1}$ & $\%$ \\
\hline 0 & 103,9 & 15,1 & 79,9 & 2,1 & 13,4 & 13.402 & 100 \\
\hline 40 & 106,1 & 15,7 & 82,3 & 2,1 & 13,3 & 13.521 & 101 \\
\hline 80 & 105,1 & 14,9 & 83,7 & 2,1 & 13,3 & 13.099 & 98 \\
\hline 160 & 102,3 & 15,1 & 83,4 & 2,1 & 13,1 & 12.902 & 100 \\
\hline 320 & 99,3 & 13,0 & 86,7 & 2,1 & 13,1 & 13.734 & 101 \\
\hline Média & 103,3 & 14,8 & 83,2 & 2,1 & 13,2 & 13.332 & 100 \\
\hline Valor de F & 1,17 & 1,99 & 0,26 & 0,76 & 0,48 & 0,11 & 0,58 \\
\hline CV\% & 5,3 & 11,29 & 12,81 & 1,10 & 4,62 & 16,69 & 4,48 \\
\hline
\end{tabular}

A influência da adubação potássica na produtividade da cultura da soja é relatada como baixa e a maioria das respostas são obtidas em solos com baixo teor de $\mathrm{K}$ (MASCARENHAS et al., 1994; SCHERER, 1998a; SCHERER, 1998b; LANA et al., 2002; LOPES, 2007; SERAFIM et al., 2012). Assim poucos trabalhos apresentam respostas significativas a doses de $\mathrm{K}$ em solos com alto teor (PETTER et al., 2012). No sistema estudado, além de o solo apresentar teores adequados de $\mathrm{K}$, a palhada de milho neste sistema na região disponibiliza altas quantidades de $\mathrm{K}$ durante sua decomposição, a qual sincroniza com o crescimento da soja.

A cultura da soja normalmente é pouco responsiva a adubação potássica, pois tem baixa exigência, somasse a isso a grande quantidade de $\mathrm{K}$ advindo da palhada de milho (162 $\mathrm{kg} \mathrm{ha}^{-1}$ na safra 2013-14 e $202 \mathrm{~kg} \mathrm{ha}^{-1}$ no tratamento sem adição de K na safra 2014-15) resultam na não influência das doses de $\mathrm{K}$. O teor inicial de $\mathrm{K}$ no solo (Tabela 1) está acima do teor considerado limitante, $53 \mathrm{mg} \mathrm{dm}^{-3}$ (SOUSA e LOBATO, 2004) e $70 \mathrm{mg} \mathrm{dm}^{-3}$ (PETTER et al., 2012). A soja usou as reservas de $\mathrm{K}$ do solo e/ou as reservas dos resíduos culturais para suprir suas necessidades fisiológicas.

Cultura Agronômica, Ilha Solteira, v.27, n.2, p.310-326, 2018 
Tabela 3. Características agronômicas: Altura de planta (ALT), Altura de inserção da primeira vagem (IPV), número de vagens por planta (VPP), grãos por vagem $(\mathrm{GV})$, massa de 100 grãos (M100) e massa de seca (MS) e produção relativa (PROD) da soja safra 201415 em função das doses de $\mathrm{K}$ e da presença ou ausência do consórcio com braquiária, Sorriso-MT.

\begin{tabular}{lccccccc}
\hline \multirow{2}{*}{ Tratamentos } & ALT & IPV & VPP & GV & M100 & MS & PROD \\
\cline { 2 - 8 } & \multicolumn{2}{c}{--- cm---- } & \multicolumn{2}{c}{ Quantidade } & g & $\mathrm{kg} \mathrm{ha}^{-1}$ & $\%$ \\
\hline Doses & & & & & & & \\
0 & 69,0 & 12,9 & 61,1 & 2,1 & 10,8 & 10.065 & 99 \\
40 & 68,3 & 13,4 & 56,2 & 2,0 & 11,2 & 10.832 & 102 \\
80 & 67,1 & 13,6 & 56,2 & 2,1 & 11,3 & 9.550 & 97 \\
160 & 70,7 & 13,1 & 57,4 & 2,1 & 11,1 & 9.593 & 101 \\
320 & 67,0 & 12,0 & 65,7 & 2,1 & 11,2 & 9.937 & 105 \\
\hline Consórcio & & & & & & & \\
Com & 69,5 & 13,3 & 61,1 & 2,1 & 11,2 & 10.246 & 99 \\
Sem & 67,4 & 12,7 & 57,6 & 2,1 & 11,1 & 9.743 & 103 \\
\hline Média & 68,4 & 13,0 & 59,3 & 2,1 & 11,1 & 9.995 & 101 \\
\hline Análise de variação $($ valor de F) & & & & & \\
Doses & 0,93 & 2,44 & 1,38 & 1,58 & 1,58 & 1,42 & 1,42 \\
Consórcio & 2,91 & 3,76 & 1,29 & 0,77 & 1,18 & 1,83 & 2,16 \\
D x C & 0,44 & 0,81 & 1,16 & 0,31 & 1,14 & 1,94 & 1,03 \\
CV1\% & 7,22 & 9,78 & 18,56 & 2,48 & 4,40 & 13,73 & 7,83 \\
CV2\% & 6,28 & 8,38 & 18,42 & 2,86 & 4,92 & 13,17 & 8,89 \\
\hline
\end{tabular}

Assim a não resposta condiz com os resultados de Scherer (1998b), em que teores entre 60 a $80 \mathrm{mg} \mathrm{dm}^{-3}$, a resposta da cultura da soja a adubação potássica é muito baixa ou inexistente, no entanto Petter et al. (2012) observaram resposta da soja em solo com teor de $\mathrm{K}$ de $77 \mathrm{mg} \mathrm{dm}^{-3}$, com incremento na produtividade até a dose de $97 \mathrm{~kg} \mathrm{ha}^{-1}$ de $\mathrm{K}_{2} \mathrm{O}$.

As condições climáticas durante a condução das safras de soja foram favoráveis, justificando a não resposta de todos os parâmetros avaliados. Na safra 2013-14 durante sua condução ocorreu uma precipitação de $1.788 \mathrm{~mm}$, com um período de apenas cinco dias sem chuvas. A safra 2014-15, as condições foram um pouco menos propicias, mas nada que prejudicasse a absorção de $\mathrm{K}$ e interferisse nos resultados, a precipitação acumulada foi de $950 \mathrm{~mm}$, com um veranico de 13 dias, que ocorreu na fase inicial da soja, situação comum na região para o início do plantio.

Uma precipitação bem distribuída e em quantidade adequada proporcionaram um bom uso do $\mathrm{K}$ do solo, pois a umidade do solo apresenta grande influência na absorção e uso do K pelas plantas, segundo Serafim et al. (2012) o teor de K e a umidade do solo tem efeito compensatório entre si, em que um fator reduz o efeito da deficiência do outro. Outro fator é que a precipitação também influência na decomposição e liberação de $\mathrm{K}$ dos resíduos vegetais sobre o solo (CALONEGO et al., 2005). Assim além de propiciar melhor 
condições para absorção de $\mathrm{K}$, a precipitação adequada também contribui para acelerar a disponibilização do $\mathrm{K}$ contido nos restos culturais sobe o solo sendo de grande valia para a nutrição da soja.

No milho safra 2013-14 com exceção da altura de inserção da espiga, massa de 100 grãos e produção as demais variáveis não apresentaram respostas ao consórcio e doses de $\mathrm{K}$ aplicadas (Tabela 4 e 5). A utilização do consórcio normalmente tem grande efeito depressivo na produtividade de milho e nas demais variáveis avaliadas, principalmente no $1^{\circ}$ ano de cultivo da cobertura, contudo se observa que esta influenciou apenas a altura de espiga, isto se deve ao baixo crescimento da braquiária na área, o que resultou em baixa produtividade de massa seca, próxima a 1,0 $\mathrm{t} \mathrm{ha}^{-1}$. Este fator tem que ser levado em consideração para todas as safras avaliadas que possivelmente teriam algum efeito da braquiária, seja positivo ou negativo.

Tabela 4. Características agronômicas: altura de planta (ALT), altura de inserção da espiga (IE), comprimento do colmo (CC), comprimento de espiga (CE), diâmetro do colmo (DC), diâmetro da espiga (DE) e diâmetro do sabugo (DS) do milho safra 2013-14 em função das doses de K e da presença ou ausência do consórcio com braquiária, Sorriso-MT.

\begin{tabular}{|c|c|c|c|c|c|c|c|}
\hline \multirow[t]{2}{*}{ Tratamento } & ALT & IE & $\mathrm{CC}$ & $\mathrm{CE}$ & $\mathrm{DC}$ & $\mathrm{DE}$ & DS \\
\hline & \multicolumn{4}{|c|}{ |-----------------------cm--------------------- } & \multicolumn{3}{|c|}{------------mm------------ } \\
\hline \multicolumn{8}{|c|}{ ( } \\
\hline 0 & 281 & 132 & 21,3 & 15,8 & 15,7 & 53,2 & 31,0 \\
\hline 40 & 282 & 133 & 21,3 & 15,9 & 15,5 & 53,8 & 30,5 \\
\hline 80 & 281 & 132 & 21,5 & 15,8 & 15,7 & 53,8 & 30,0 \\
\hline 160 & 282 & 134 & 21,5 & 15,9 & 15,8 & 53,8 & 31,2 \\
\hline 320 & 282 & 134 & 21,2 & 15,7 & 15,9 & 54,1 & 31,1 \\
\hline \multicolumn{8}{|l|}{ Consórcio } \\
\hline Com & 282 & $132 \mathrm{~b}$ & 21,5 & 15,9 & 15,8 & 53,8 & 30,7 \\
\hline Sem & 281 & $134 \mathrm{a}$ & 21,2 & 15,8 & 15,7 & 53,7 & 30,8 \\
\hline Média & 281 & 133 & 21,4 & 15,8 & 15,7 & 53,8 & 30,8 \\
\hline \multicolumn{8}{|c|}{ Análise de variação (valor de F) } \\
\hline Doses & 0,08 & 0,46 & 1,05 & 0,19 & 0,29 & 0,86 & 1,39 \\
\hline Consórcio & 0,05 & $7,74 *$ & 3,66 & 0,19 & 0,27 & 0,06 & 0,10 \\
\hline $\mathrm{D} \times \mathrm{C}$ & 0,19 & 0,17 & 0,18 & 1,21 & 2,08 & 1,43 & 0,89 \\
\hline CV1\% & 2,30 & 2,69 & 1,90 & 4,35 & 5,49 & 2,07 & 4,56 \\
\hline $\mathrm{CV} 2 \%$ & 2,08 & 2,49 & 2,80 & 5,95 & 4,57 & 2,92 & 4,72 \\
\hline
\end{tabular}

Letras diferentes na coluna diferem a 5\% de probabilidade pelo teste de Tukey.

Observa-se a baixa variação entre as médias dos tratamentos, para as variáveis: altura de planta; comprimento do colmo e espiga; diâmetro do colmo, espiga e sabugo; fileira por espiga e grãos por fileira. Também se observa um baixo coeficiente de variação, não passando de $6 \%$ para estas variáveis, valor bom para experimentos de campo. Esta baixa variação demostra que em solos com teor de $\mathrm{K}$ no solo adequado mesmo sob estresse 
hídrico estas variáveis não são afetadas pelo fornecimento adicional de K. Entre as variáveis que não apresentaram resposta aos tratamentos a produção de massa seca foi a que apresentou a maior variação entre os tratamentos $(5 \%)$.

A altura de inserção da espiga no milho safra 2013-14 apresentou diferença pelo teste F para o fator consórcio, sendo que a presença de braquiária diminuiu a altura da espiga. A diferença ocorreu devido ao baixo coeficiente de variação $(2,49 \%)$ e ao acaso, com as médias dos tratamentos apresentando diferença de apenas dois centímetros $(1,5 \%)$, sem influencia pratica durante a colheita. Segundo Possamai et al. (2001) a altura de inserção de espiga mais alta apresenta vantagem na colheita mecanizada, com maior pureza e menor perda.

Tabela 5. Componentes de produção e produção relativa do milho safra 2013-14 em função das doses de K e da presença ou ausência do consórcio com braquiária, Sorriso-MT.

\begin{tabular}{lccccc}
\hline Tratamento & $\begin{array}{c}\text { Fileiras por } \\
\text { espiga }\end{array}$ & $\begin{array}{c}\text { Grãos por } \\
\text { fileira }\end{array}$ & $\begin{array}{c}\text { Massa de } \\
100 \text { grãos }\end{array}$ & Matéria seca & Produção \\
\cline { 2 - 6 } Doses & \multicolumn{2}{c}{ Unidade } & $\mathrm{g}$ & $\mathrm{kg} \mathrm{ha}^{-1}$ & $\%$ \\
0 & 18,8 & 30,6 & 31,6 & 7.559 & 100 \\
40 & 18,6 & 31,0 & 32,0 & 7.531 & 111 \\
80 & 18,5 & 30,6 & 32,7 & 7.256 & 113 \\
160 & 18,5 & 30,9 & 32,4 & 7.611 & 124 \\
320 & 18,5 & 31,3 & 31,7 & 7.337 & 123 \\
\hline Consórcio & & & & \\
Com & 18,6 & 31,2 & 32,1 & 7.448 & 114 \\
Sem & 18,6 & 30,6 & 32,1 & 7.470 & 115 \\
\hline Média & 18,6 & 30,9 & 32,1 & 7.459 & 114 \\
\hline Análise de variação (valor de F) & & & & \\
Dose & 0,41 & 0,48 & $3,71 *$ & 0,36 & $9,22^{*}$ \\
Consórcio & 0,05 & 1,27 & 0,06 & 0,01 & 0,03 \\
D x C & 0,3 & 0,79 & $3,17 *$ & 0,59 & 0,06 \\
CV1\% & 2,98 & 3,95 & 2,34 & 10,91 & 8,73 \\
CV2\% & 3,56 & 5,83 & 1,81 & 11,84 & 7,83 \\
\hline
\end{tabular}

A massa de 100 grãos do milho safra 2013-14 apresentou interação entre as doses e o consórcio com braquiária, embora tenha ocorrido interação entre os fatores a resposta é muito similar (Figura 2A). As doses de máxima resposta foram 166 e $157 \mathrm{~kg} \mathrm{ha}^{-1}$ de $\mathrm{K}_{2} \mathrm{O}$, respectivamente para o manejo com e sem a presença do consórcio com braquiária. As doses de K não influenciaram o número de fileiras e grãos por fileiras, assim a nutrição mais adequada proporcionou uma maior massa dos grãos. Resultados estes que corroboram com Büll (1993), todavia Valderrama et al. (2011) e Petter et al. (2016) obtiveram resultado diferente, em que as doses de $\mathrm{K}$ aumentaram o número de fileiras por espiga, aumentando

Cultura Agronômica, Ilha Solteira, v.27, n.2, p.310-326, 2018 
assim o número de grãos por espiga, condição que exerceu competição por fotoassimilados, resultando em grãos de menor massa.
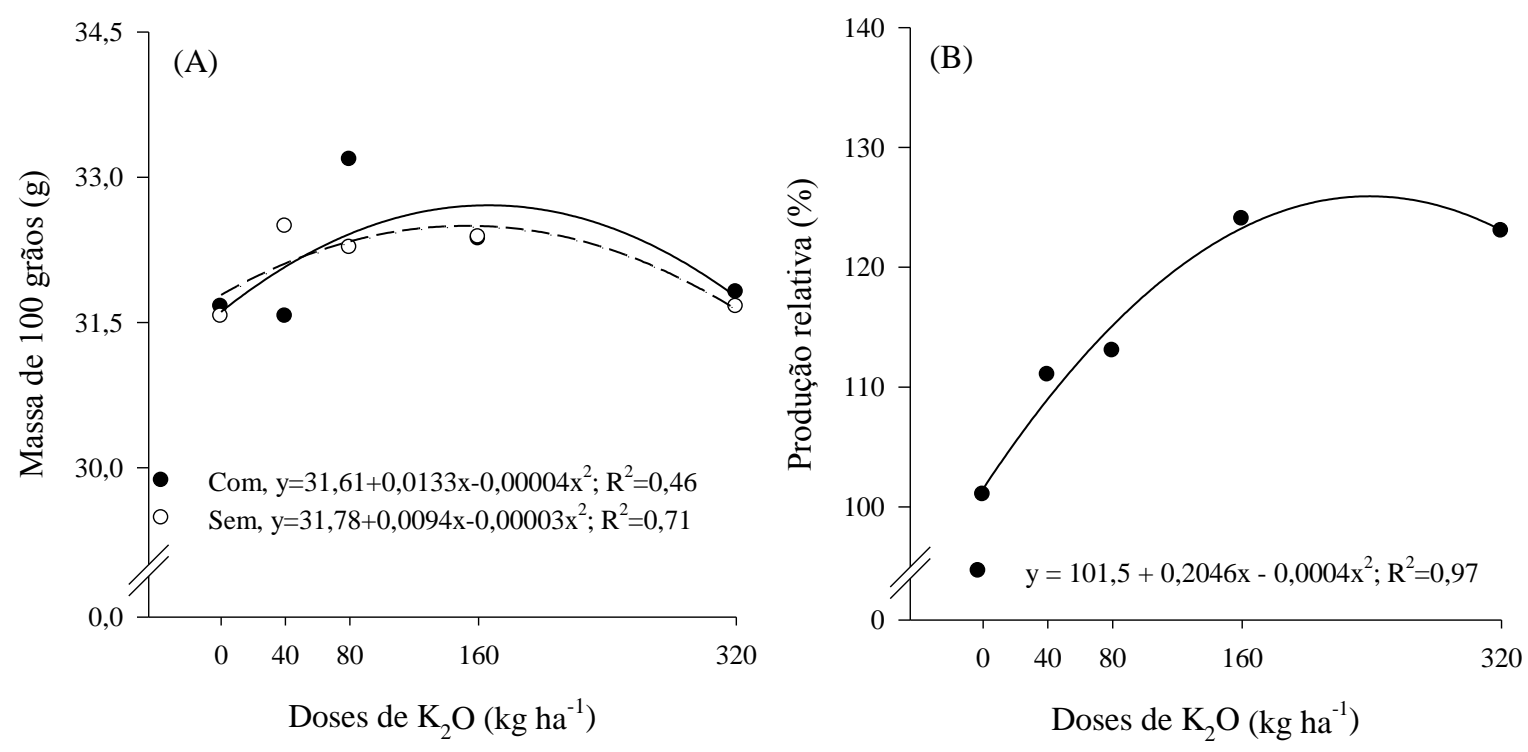

Figura 2. Massa de 100 grãos para os manejos com e sem consórcio (A) e produção relativa (B) em função das doses de K aplicadas, para o milho safra 2013-14, sorriso-MT.

O milho safra 2013-14 apresentou no tratamento sem adubação e sem consórcio (tratamento controle para o cálculo da produtividade relativa) uma produtividade de 7.168 $\mathrm{kg} \mathrm{ha}^{-1}$. A resposta às doses de $\mathrm{K}$ foi quadrática, com máxima produção na dose de $256 \mathrm{~kg}$ $\mathrm{ha}^{-1}$ de $\mathrm{K}_{2} \mathrm{O}$, esta dose proporcionou um incremento de $28 \%$ na produtividade, 33 sacas, representando um grande ganho na produção (Figura 2B). Os dados obtidos diferem dos obtidos por Takasu et al. (2014) e Valderrama et al. (2011) que não observaram efeito das doses de K na produção de grãos do milho, contudo Petter et al. (2016) obtiveram resposta às doses de $\mathrm{K}$, porém a produtividade máxima foi obtida na dose de $53 \mathrm{~kg} \mathrm{ha}^{-1}$ de $\mathrm{K}_{2} \mathrm{O}$, mesmo o teor no solo sendo inferior ao do presente estudo. O milho safra 2014-15 apresentou resposta apenas para o número de grãos por fileira de grãos na espiga, sendo está influenciada pelas doses de $\mathrm{K}$, as demais variáveis não apresentaram resposta (Tabela 6).

O número de grãos por fileira de grãos na espiga apresentou comportamento quadrático (Figura 3), sendo que a dose de máxima resposta foi $139 \mathrm{~kg} \mathrm{ha}^{-1}$, este incremento não foi suficiente para que se tivesse um aumento significativo na produtividade. $O$ efeito significativo no número de grãos por fileira também foi obtido por Valderrama et al. (2011), tendo comportamento linear as doses de $\mathrm{K}_{2} \mathrm{O}$, sendo que a dose máxima empregada foi de $120 \mathrm{~kg}$, o que condiz com encontrado no presente estudo. 
Tabela 6. Componentes de produção, produção relativa do milho safra 2014-15 e produção acumulada nos quatro cultivos, em função das doses de $\mathrm{K}$ e da presença ou ausência do consórcio com braquiária, Sorriso-MT.

\begin{tabular}{|c|c|c|c|c|c|}
\hline \multirow[t]{2}{*}{ Tratamento } & $\begin{array}{c}\text { Fileiras por } \\
\text { espiga }\end{array}$ & $\begin{array}{l}\text { Grãos por } \\
\text { fileira }\end{array}$ & $\begin{array}{l}\text { Massa de } \\
100 \text { grãos }\end{array}$ & Produção & $\begin{array}{c}\text { Produção } \\
\text { Acumulada }\end{array}$ \\
\hline & \multicolumn{2}{|c|}{ Unidade } & $\mathrm{g}$ & \multicolumn{2}{|c|}{--------------\%------------ } \\
\hline \multicolumn{6}{|l|}{ Doses } \\
\hline 0 & 15,3 & 33,7 & 31,2 & 99 & 100 \\
\hline 40 & 15,1 & 33,8 & 30,6 & 101 & 104 \\
\hline 80 & 15,3 & 34,7 & 31,5 & 100 & 104 \\
\hline 160 & 15,2 & 34,2 & 30,8 & 104 & 110 \\
\hline 320 & 15,3 & 32,8 & 30,4 & 104 & 109 \\
\hline \multicolumn{6}{|l|}{ Consórcio } \\
\hline Com & 15,2 & 33,9 & 31,0 & 100 & - \\
\hline Sem & 15,4 & 33,8 & 30,8 & 103 & - \\
\hline Média & 15,3 & 33,8 & 30,9 & 102 & 106 \\
\hline \multicolumn{6}{|c|}{ Analise de variação (valor de F) } \\
\hline Dose & 0,42 & $8,20 *$ & 2,06 & 1,29 & $8,50 *$ \\
\hline Consórcio & 2,62 & 0,14 & 0,36 & 3,55 & - \\
\hline $\mathrm{D} \times \mathrm{C}$ & 0,20 & 0,33 & 1,29 & 0,20 & - \\
\hline CV1\% & 2,49 & 2,17 & 3,02 & 6,18 & 2,96 \\
\hline CV2\% & 2,86 & 5,50 & 3,93 & 5,55 & - \\
\hline
\end{tabular}

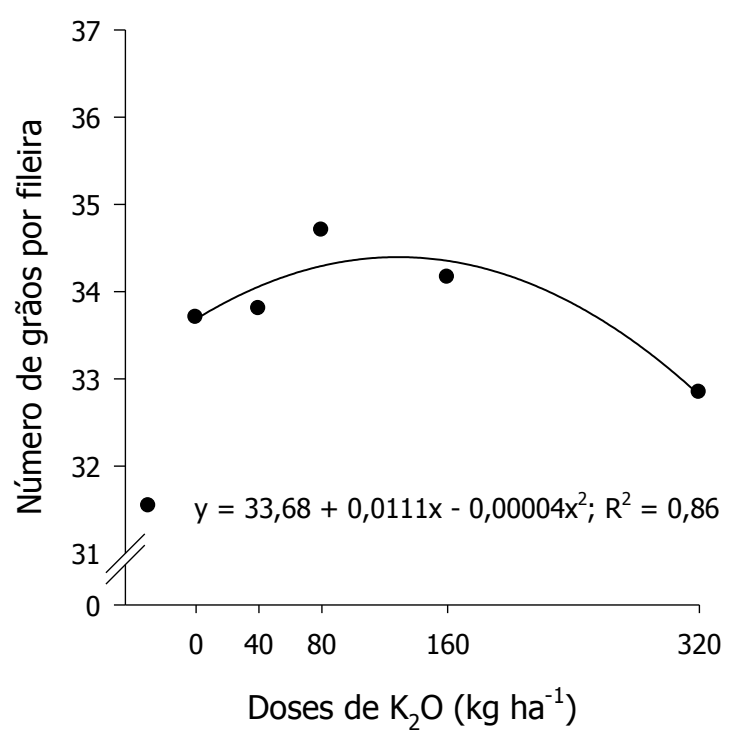

Figura 3. Número de grãos por fileira em função das doses de $\mathrm{K}$ aplicadas, para o milho safra 2014-15, sorriso-MT.

A produção relativa do milho safra 2014-15 não foi afetada pelas doses de $\mathrm{K}$, com a produtividade de $9.753 \mathrm{~kg} \mathrm{ha}^{-1}$ na parcela referência (parcela sem adubação com $\mathrm{K}$ e sem 
consórcio). $\mathrm{O}$ entendimento da produtividade dos grãos está diretamente ligado às condições climáticas e a janela de plantio de ambas as safras. Na safra 2013-14 há resposta às doses de K e a safra 2014-15 não houve resposta. A safra 2013-14 sofreu com a baixa precipitação durante o seu desenvolvimento, apenas $227 \mathrm{~mm}$, sendo a última chuva expressiva aos 29 dias após a semeadura, condição atípica para a região, o que comprometeu a produtividade. Na safra 2014-15 não houve déficit hídrico e a precipitação acumulada de $1.053 \mathrm{~mm}$, com chuvas até 98 dias da semeadura.

Este evento ocorreu e foi agravado pela semeadura tardia do milho safra 2013-14, no início de março, sendo que a janela ideal levando em consideração as características do solo e da cultivar deve ser até 31 de janeiro (MAPA, 2017). O milho safra 2014-15 foi semeado na janela apropriada, início de fevereiro. É importante ressaltar que ambas as precipitações não são normais para a região, dados retirados da mesma estação meteorológica mostram que a média dos cinco anos anteriores, é de $950 \mathrm{~mm}$, abrangendo o período de fevereiro a julho.

Como acima discutido para a soja, sabe-se da grande importância da umidade do solo para a adequada absorção de $\mathrm{K}$, assim em condições de deficiência hídrica a maior disponibilidade de $\mathrm{K}$ no solo facilitou sua absorção e como consequência respondeu em maior produtividade (milho safra 2013-14) enquanto em condições ideais de umidade no solo, mesmo as concentrações mais baixas de $\mathrm{K}$, devido apenas ao efeito residual, atenderam a demanda da cultura do milho.

Mesmo somente a produtividade do milho safra 2013-14 apresentando resposta às doses de $\mathrm{K}$, ao se calcular a produção acumulada nos quatro cultivos, se tem resposta ao $\mathrm{K}$ aplicado (Figura 4), com resposta quadrática, a máxima resposta na aplicação de $253 \mathrm{~kg} \mathrm{ha}^{-1}$ de $\mathrm{K}_{2} \mathrm{O}$, com $10 \%$ de incremento na produção, em relação ao tratamento sem adição de K.

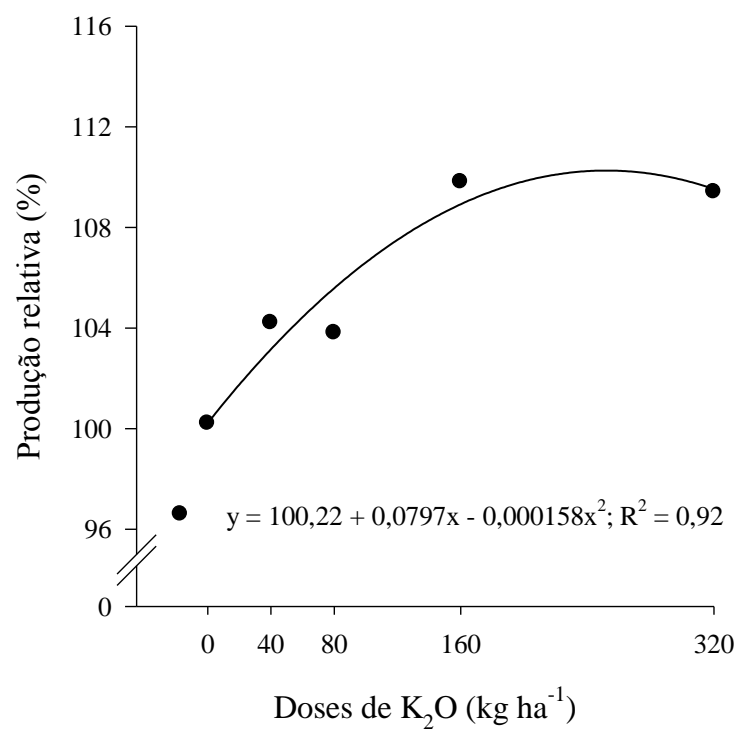

Figura 4. Produção acumulada nos quatros cultivos em função das doses de K aplicadas, Sorriso-MT.

Cultura Agronômica, Ilha Solteira, v.27, n.2, p.310-326, 2018 
Observa-se que o uso excessivo de fertilizantes não gera ganhos pelo aumento da produtividade, principalmente na soja semeada sobre a palhada residual de milho, que apresenta uma grande reserva de $\mathrm{K}$ e que mantém o suprimento adequado do nutriente. As respostas foram notadas apenas no milho sob estresse hídrico, devido a este fator controlar a disponibilidade do elemento para a planta, pela influência direta no fluxo de massa no solo e porque na condição de estresse hídrico a planta fecha estômatos, reduzindo a absorção do mesmo. Um manejo a ser adotado seria fazer a adubação com potássio mais pesada no milho, cultura mais sujeita a passar por veranicos, e a soja se beneficiaria do K presente na palha do mesmo. Mesmo não se tendo resposta na maioria das safras avaliadas não se recomenda a não aplicação de $\mathrm{K}$, devido a rápida depleção dos teores de $\mathrm{K}$ no solo, devido a grande exportação causada pelo cultivo intensivo (soja-milho) e grande lixiviação em áreas de elevada precipitação.

\section{CONCLUSÃO}

Não se tem efeito das doses de K na soja, contudo se tem efeito residual no milho plantado em sequência.

A soja não responde a aplicação de potássio em sistemas com teor de $\mathrm{K}$ no solo adequado.

Quando sob estresse hídrico, mesmo com teores altos de K no solo, o milho responde ao aumento de potássio no solo. Já sob condições climáticas adequadas, com chuvas bem distribuídas não se observa resposta.

\section{AGRADECIMENTO}

Ao Eng. Agr. Ivan Bedin pela cessão da área experimental e pelo apoio na execução do experimento, a Fundação Mato Grosso na pessoa de Jose Antônio Costa pela disponibilização dos dados climáticos, a fundação AGRISUS pelo apoio financeiro para execução do projeto, e a fundação de amparo a pesquisa FAPEMAT pela concessão de bolsa de estudos para o primeiro autor.

\section{REFERÊNCIAS BIBLIOGRÁFICAS}

BORGES, I. D. Marcha de absorção de nutrientes e acúmulo de matéria seca em milho. 2006. 115 f. Tese (Doutorado em Agronomia). Universidade federal de Lavras, Lavras, 2006.

BRADY N. C.; WEIL, R. R. Ciclagem de nutrientes e Fertilidade do solo. In. BRADY, N. C.; WEIL, R. R. Elementos da natureza e propriedades dos solos. 3. ed. Porto Alegre: Bookman, 2013. cap. 12, p. 437-499. 
BÜLL, L. T. Nutrição mineral do milho. In: BÜLL, L. T.; CANTARELLA, H. (Ed.). Cultura do milho: Fatores que afetam a produtividade. Piracicaba: Potafos, 1993. cap. 5, p. 63-145.

CALONEGO, J. C.; FOLONI, J. S. S.; ROSOLEM, C. A. Lixiviação de potássio da palha de plantas de cobertura em diferentes estágios de senescência após a dessecação química. Revista Brasileira de Ciências do Solo, Viçosa, v. 29, n. 1, p.99-108, 2005.

COELHO, A. M. Nutrição e Adubação do Milho. Sete Lagoas: Embrapa Milho e Sorgo, 2006. 10 p. (Circular Técnica, 78).

COMPANHIA NACIONAL DE ABASTECIMENTO - CONAB. Series históricas. 2015. Disponível em: <http://www.conab.gov.br/conteudos.php?a=1252\&t=>. Acesso em: 4 jan. 2016.

CRUZ, T. V.; PEIXOTO, C. P.; MARTINS, M. C. Crescimento e produtividade de soja em diferentes épocas de semeadura no oeste da Bahia. Scientia Agraria, Curitiba, v. 11, n. 1, p.33-42, 2010.

EMPRESA BRASILEIRA DE PESQUISA AGROPECUÁRIA - EMBRAPA. Manual de Métodos de Análise de Solos. 3.ed. Brasília: Embrapa solos, 2017. 573 p.

EMPRESA BRASILEIRA DE PESQUISA AGROPECUÁRIA - EMBRAPA. Sistema brasileiro de classificação de solos. 3.ed. Brasília: Embrapa, 2013. 353 p.

EMPRESA BRASILEIRA DE PESQUISA AGROPECUÁRIA - EMBRAPA. Tecnologias de produção de soja - Região Central do Brasil 2012 e 2013. Londrina: Embrapa soja, 2011. 261 p. (Embrapa Soja, Sistemas de Produção, 15).

INTERNATIONAL PLANT NUTRITION INSTITUTE - IPNI. Fertilizantes. 2014. Disponível em: 〈http://brasil.ipni.net/article/BRS-3132\#consumo>. Acesso em: 4 jan. 2016.

LANA, R. M. Q.; HAMAWAKI, O. T.; LIMA, L. M. L.; ZANÃO JÚNIOR, L. A. Resposta da soja a doses e modos de aplicação de potássio em solo de cerrado. Bioscience Journal, Uberlândia, v. 18, n. 2, p.17-23, 2002.

LOPES, A. A. Nitrogênio e potássio na cultura da soja em argissolo vermelho, derivado de arenito Caiuá. 2007. 46 f. Dissertação (Mestrado em Agronomia) - Universidade do Oeste Paulista, Presidente Prudente, 2007.

MINISTÉRIO DA AGRICULTURA, PECUÁRIA E ABASTECIMENTO - MAPA. Zoneamento Agrícola, Milho. 2017. Disponível em: <http://www.agricultura.gov.br/assuntos/riscos-seguro/risco-agropecuario/portarias/safravigente/mato-grosso>. Acesso em: 08 ago. 2017.

MASCARENHAS, H. A. A.; TANAKA, R. T.; PEREIRA, J. C. V. N. A.; GALlO, P. B.; BATAGLiA, O. C. Efeito de adubos potássicos na produção da soja. Scientia Agricola, Piracicaba, v. 51, n. 1, p.82-89, 1994.

Cultura Agronômica, Ilha Solteira, v.27, n.2, p.310-326, 2018 
OLIVEIRA JUNIOR, A.; CASTRO, C.; OLIVEIRA, F. A.; JORDÃO, L. T. Adubação potássica da soja: cuidados no balanço de nutrientes. Informações Agronômicas. n. 143. . Piracicaba: IPNI, 2013. 10 p.

PETTER, F. A.; ANDRADE, F. R.; ZUFFO, A. M.; MONTEIRO, M. M. S.; PACHECO, L. P.; ALMEIDA, F A. Doses e épocas de aplicação de potássio no desempenho agronômico do milho no cerrado piauiense. Comunicata Scientiarum, Bom Jesus, v. 7, n. 3, p.372-382, 2016.

PETTER, F. A.; SIlVA, J.; PACHECO, A. P.; AlMEIDA, F. A.; AlCÂNTARA NETO, F.; ZUFFO, A. M.; LIMA, L. B. Desempenho agronômico da soja a doses e épocas de aplicação de potássio no cerrado piauiense. Revista de Ciências Agrárias, Belém, v. 55, n. 3, p.190-196, 2012.

POSSAMAI, J. M.; SOUZA, C. M.; GALVÃO, J. C. C. Sistemas de preparo do solo para o cultivo do milho safrinha. Bragantia, Campinas, v. 60, n. 2, p.79-82, 2001.

RAIJ, B. Van.; CANTAREllA, H.; QUAGGIO, J. A.; FURLANI, A. M. C. Recomendações de Adubação e Calagem para o Estado de São Paulo. 2. ed. Campinas: Instituto Agronômico Campinas, 1997. 285 p. (Boletim técnico 100).

SCHERER, E. E. Níveis críticos de potássio para a soja em latossolo húmico de Santa Catarina. Revista Brasileira de Ciência do Solo, Viçosa, v. 22, n. 1, p.57-62, 1998a.

SCHERER, E. E. Resposta da soja à adubação potássica em latossolo húmico distrófico num período de doze anos. Revista Brasileira de Ciência do Solo, Viçosa, v. 22, n. 1, p.49-55, $1998 b$.

SERAFIM, M. E.; ONO, F. B.; ZEVIANI, W. M.; NOVELINO, J. O.; SILVA, J. V. Umidade do solo e doses de potássio na cultura da soja. Revista Ciência Agronômica, Fortaleza, v. 43, n. 2, p.222-227, 2012.

SOUSA, D. M. G.; LOBATO, E. Cerrado, correção do solo e adubação. 2. ed. Brasília: Embrapa Informação Tecnológica, 2004. 416 p.

TAKASU, A. T.; HAGA, K. I.; RODRIGUES, R. A. F.; ALVES, C. J. Produtividade da cultura do milho em resposta à adubação potássica. Revista Brasileira de Milho e Sorgo, Brasília, v. 13, n. 2, p.154-161, 2014.

VALDERRAMA, M.; BUZETTI, S.; BENETT, C. G. S.; ANDREOTTI, M.; TEIXEIRA FILHO, M. C. M. Fontes e doses de NPK em milho irrigado sob plantio direto. Pesquisa Agropecuária Tropical, Goiânia, v. 41, n. 2, p.254-263, 2011.

VON PINHO, R. G.; BORGES, I. D.; PEREIRA, J. L. A. R.; REIS, M. C. Marcha de absorção de macronutrientes e acúmulo de matéria seca em milho. Revista Brasileira de Milho e Sorgo, Brasília, v. 8, n. 2, p.157-173, 2009.

Cultura Agronômica, Ilha Solteira, v.27, n.2, p.310-326, 2018 
WENDLING, A.; ELTZ, F. L. F.; CUBILlA, M. M.; AMADO, T. J. C.; MIELNICZUK, J. Recomendação de adubação potássica para trigo, milho e soja sob sistema plantio direto no Paraguai. Revista Brasileira de Ciência do Solo, Viçosa, v. 32, n. 5, p.1929-1939, 2008. 